\title{
Rancang Bangun Aplikasi Pemesanan Molly Molen Malang Berbasis Android MenggunakanMetode Waterfall
}

\author{
Ageng Widjaya Saputra*1, Wahyu Andyka Kusuma ${ }^{2}$, Wildan Suharso ${ }^{3}$ \\ 1,2,3 Teknik Informatika/Universitas Muhammadiyah Malang \\ agengwidjaya12@gmail.com¹, wahyukusuma@umm.ac.id², wsuharso@umm.ac.id ${ }^{3}$
}

\begin{abstract}
Abstrak
Aplikasi pemesanan molly molen merupakan aplikasi yang dirancangn untuk mengatasi permasalahan interaksi customer dan penjual molly. Kebutuhan adanya aplikasi ini muncul karena kurang efektifnya pemesanan melalui media social seperti whatsapp dan instagram. Metode yang digunakan dalam pembuatan aplikasi ialah waterfall dengan terlebih dahulu melakukan analisa, desain sistem, implementasi, testing, dan maintenance. Aplikasi dikembangkan dalam dua bentuk, yakni aplikasi android dan web. Pengujian dilakukan menggunakan blackbox dengan menguji fungsi fungsi yang telah dirancang. Hasil pengujian menunjukkan bahwa aplikasi dapat berjalan dengan baik, secara fungsional sistem dan dapat menghasilkan output yang diharapkan. Sehingga dapat disimpulkan aplikasi pemesanan molly molen sudah sesuai dengan tujuan utama pembuatan aplikasi.
\end{abstract}

Kata Kunci: Aplikasi Pemesanan, Android, Waterfall

\begin{abstract}
The Molly Molen ordering application is an application that is designed to solve the customer and seller interaction problems with Molly. The need for this application arises because of the ineffectiveness of ordering through social media such as WhatsApp and Instagram. The method used in making an application is a waterfall by first conducting analysis, system design, implementation, testing, and maintenance. The application was developed in two forms, namely android and web applications. Testing is done using a blackbox by testing the functions that have been designed. The test results show that the application can run well, functionally the system and can produce the expected output. So, it can be concluded that the application of ordering molly molen is in accordance with the main purpose of making the application.
\end{abstract}

Keywords: Ordering Application, Android, Waterfall

\section{Pendahuluan}

Menjamurnya franchise kuliner luar seperti KFC, McDonalds, Hoka-Hoka Bento, Hanamasa, Pizza hut di beberapa tempat yang strategis di Indonesia memberi dampak buruk bagi pengusaha kuliner mikro kecil dan menengah dalam negeri. Usaha Mikro Kecil dan Menengah (UMKM) khususnya di sector kuliner butuh strategi pengembangan kokoh dan perlu melibatkan elemen-elemen besar sampai terkecil serta instrument hukum [1].

Oleh sebab itu pengusaha kecil dan menengah harus meningkatkan kualitas layanan sehingga dapat menambah keuntungan dari UMKM tersebut, penelitian oleh Gamaliel [2] menyimpulkan penggunaan teknologi canggih dapat meningkatkan kualitas layanan, produk, serta proses pengerjaan lebih efektif dan efisien bagi UMKM sendiri.

Salah satu UMKM di Kota Malang adalah Molly Molen, berlokasi di kawasan Jalan Bendungan Riam Kanan Nomor 4 Kota Malang. Usaha ini merupakan salah satu produk rumahan yaitu kuliner jajanan pisang berlapis adonan tepung terigu dan mempunyai varian rasa sangat menarik [3].

Dalam pemasaran menu Molly Molen, Molly Molen hanya menggunakan media sosial seperti WhatsAPP dan Instagram untuk pemesanan. Hal ini dinilai kurang interaktif dan efektif dikarenakan pelanggan baru (khususnya) tidak dapat melihat tampilan berbagai menu yang tersedia beserta harga detailnya [4]. Bagi admin pun juga kurang efektif karena harus menulis menu, jumlah pemesan, jumlah harga dan alamat secara manual [5]. Pesan antar dengan menggunakan media sosial seperti WhatsAPP dan Instagram dapat memberikan kendala seperti kasalahan komunikasi antara konsumen dan admin disebabkan oleh sinyal kurang baik, 
kesalahan dalam penulisan pesanan oleh customer dan kesalahan pembacaan pesanan oleh admin dikarenakan tidak adanya penulisan pesanan secara baku [6]. Selain itu, Molly Molen menerapkan layanan gratis ongkos kirim untuk pengiriman dengan radius jarak maksimal $5 \mathrm{~km}$. Sedang menggunakan media sosial seperti WhatsApp dan Instagram untuk penerapan gratis ongkos kirim akan memerlukan waktu lebih lama karena jarak pembeli dan jarak Molly Molen tidak bisa di dapatkan dengan cepat.

Dengan adanya permasalahan di pemesanan Molly Molen, karena masih menggunakan cara manual maka dibutuhkan kehadiran sebuah aplikasi pemesanan. Hal ini sangat penting karena keberadaan suatu aplikasi pemesanan dapat membantu penyampaian informasi produk dan harga secara detail kepada konsumen dan aplikasi tersebut bisa mempermudah penerapan layanan gratis ongkos kirim dengan jarak radius $5 \mathrm{~km}$. Selain itu melalui sebuah aplikasi pemesanan akan dapat mengakses informasi dan dibutuhkan kapan saja dan dimana saja. Dengan adanya aplikasi pemesanan akan menjelaskan bagaimana proses UMKM dalam melakukan kegiatannya sehingga dapat ditampilkan waktu pemesanan dan waktu dibutuhkan untuk mengirimkan pemesanan hingga sampai kepada pelanggan [7].

Molly molen sendiri membutuhkan sebuah aplikasi untuk segera diterapkan agar bisa menyelesaikan permasalahan yang telah dijelaskan diatas, sehingga dibutuhkan pembuatan sistem informasi dalam rentang waktu singkat. Metode yang digunakan dalam pembuatan sistem informasi ini adalah metodologi waterfall. Waterfall adalah sebuah model dari Systems Development Life Cycle (SDLC) [8].

Pada penelitian Silvester Dian Handi Permana dkk (2016), metode waterfall digunakan dalam membangun sebuah aplikasi pemesanan dan transaksi. Metode tersebut dapat lebih mudah dipahami terlebih bila hanya digunakan dalam mengembangkan perangkat lunak yang tidak begitu besar dan kompleks [9]. Penelitian lain dilakukan oleh Rinandi Awan Sagita dkk (2016), bahwa dengan menggunakan metode waterfall dapat membuat sebuah sistem informasi yang baik [10].

Penggunaan System Development Life Cycle (SDLC) cukup memadai dan menghasilkan sebuah sistem informasi berkualitas. Siklus hidup pengembangan System Development Life Cycle (SDLC adalah metodologi untuk merancang, membangun, dan memelihara informasi dan proses sistem. Waterfall adalah model pengembangan sistem yang menjadi dasar atau awal untuk model pengembangan lainnya [11]. Waterfall juga mudah di pahami karena model ini bersifat statis, dan tradisional, dengan pendekatan kerangka pengembangan secara urut di mulai dari level analisa kebutuhan sistem, desain, implementasi, pengujian dan verifikasi, serta perawatan atau maintenance, sehingga model waterfall harus menyelesaikan satu aktifitas dahulu sebelum melakukan aktifitas selanjutnya dalam penelitian ini [12].

Dalam hal ini penulis akan melakukan penelitian "Rancang Bangun Aplikasi Pemesanan Molly Molen Malang Berbasis Android Menggunakan Metode SDLC Model Waterfall" untuk pembuatan aplikasi tersebut.

\section{Tinjauan Pustakan}

\subsection{Android}

Android adalah sebuah sistem operasi untuk perangkat mobile berbasis linux yang mencangkup sistem operasi, middleware dan aplikasi. Android menyediakan platform terbuka bagi para pengembang untuk menciptakan aplikasi mereka [13]. Kelebihan dari android yaitu:

1. Complete Platform. Menyediakan tools berguna untuk membangun sebuah aplikasi yang kemudian aplikasi tersebut dapat lebih dikembangkan lagi oleh para developer.

2. Open Source Platform. Mudah dikembangkan oleh para developer karena bersifat terbuka.

3. Free Platform. Developer dengan bebas bisa mengembangkan, mendistribusikan dan memperdagangkan sistem operasi Android tanpa harus membayar royalty untuk mendapatkan license.

\subsection{Kodular}

Kodular merupakan platform yang dikembangkan untuk memudahkan build aplikasi android. Dengan menggunakan kodular pengguna sangat mungkin membuat aplikasi dengan mudah dengan editor tipe blok. Tidak diperlukan keterampilan pengkodean. Dengan Material Design UI, aplikasi sudah dapat dijalankan [14]. 


\subsection{Google Maps API}

Google map adalah layanan gratis yang telah diberikan oleh google dan sangat popular. Google Maps adalah suatu peta dunia yang dapat kita gunakan untuk melihat suatu daerah. Kita dapat menambahkan fitur Google Maps dalam web yang sudah dibuat atau pada blog kita yang berbayar maupun gratis sekalipun dengan Google Maps API adalah suatu library berbentuk JavaScript [15].

Pengetahuan yang diperlukan untuk mengembangkan Google Maps Api adalah tentang HTML dan JavaScript, sedangkan peta sudah disediakan oleh Google. Jadi kita bisa berkonsentrasi tentang data dan biarkan urusan peta ditangani oleh Google, sehingga dapat menghemat waktu. Fitur yang terdapat dalam Google Maps Api, antara lain:

a. Menampilkan peta sederhana.

Google Maps Api memungkinkan pengguna menampilkan peta sederhana pada situs web atau aplikasi mobile.

b. Marker

Marker berguna untuk memberikan petunjuk pada lokasi tertentu. Secara default, marker dapat interaktif dengan pengguna misalnya dengan menambahkan animasi seperti bounce. Marker secara default dapat ditekan dan menampilkan infobox yang menampilkan informasi mengenai lokasi tersebut.

\section{c. Info Windows}

Sebuah info windows menampilkan konten di jendela pop-up di atas peta, pada lokasi tertentu. Info windows biasanya berbentuk kotak dialog yang ujungnya berada pada titik koordinat lokasi yang ditentukan. Biasanya info windosw ditampilkan ketika marker ditekan, tetapi dapat juga langsung dilampirkan pada lokasi tertentu.

\section{d. Direction}

Direction adalah fitur Google Maps Api yang memungkinkan pengguna dapat mengetahui arah atau rute dari titik koordinat lokasi awal dan lokasi tujuan.

\subsection{Arsitektur Sistem}

Adapun arsitektur sistem dari aplikasi ini sebagaimana pada Gambar 1 berikut.

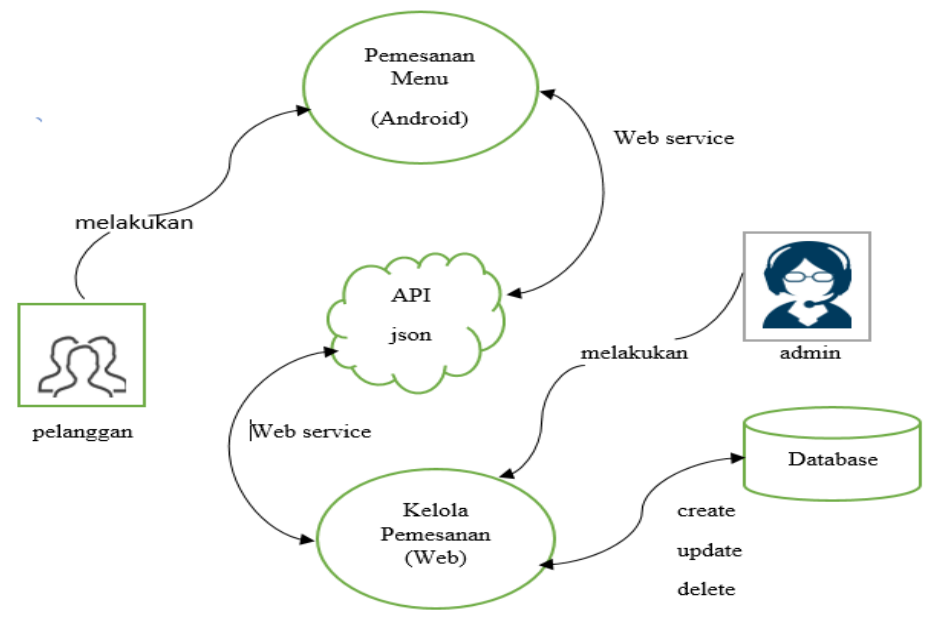

Gambar 1. Arsitektur Sistem Aplikasi Kaderisasi

Sistem pemesanan Molly Molen terbagi menjadi 2 (dua) antarmuka dengan masingmasing proses. Pelanggan melakukan proses order sedangkan admin bisa melakukan manajemen dari pemesanan. Admin bisa berpesan penting dalam web service agar pelanggan dapat melakukan order. Admin juga bisa melakukan query database untuk penambahan, pengubahan dan penghapusan data. 


\subsection{Analisa Kebutuhan Fungsional}

Kebutuhan fungsional adalah kebutuhan yang berisi proses atau layanan disediakan oleh sistem, mencakup bagaimana sistem harus bereaksi pada input tertentu dan bagaimana perilaku sistem pada situasi tertentu.

Kebutuhan fungsional sangat bergantung dari jenis perangkat lunak, pengguna sistem, dan jenis sistem dimana perangkat lunak tersebut digunakan. Kebutuhan fungsional harus dapat menggambarkan layanan-layanan yang bisa diberikan sistem kepada pengguna secara mendetail. Berikut kebutuhan fungsional yang dibutuhkan sistem ini :

1. Admin dapat melakukan input/output data transaksi pembeli.

2. Admin dapat mengelola menu Molly Molen mengenai status menu dan tarif setiap menu.

3. Admin akan menerima order ketika radius pembeli $<5 \mathrm{~km}$.

4. Customer dapat melihat tarif dan menu.

5. Customer dapat memasukkan data lengkap seperti nama, alamat dan no handphone.

6. Customer dapat melakukan order ketika jarak customer dengan Molly Molen radius $<5 \mathrm{~km}$

\subsection{Analisa Kebutuhan Non Fungsional}

Kebutuhan non-fungsional adalah kebutuhan yang menentukan atribut atau kualitas secara keseluruhan dari suatu sistem. Kebutuhan non-fungsional menempatkan batasan pada produk yang sedang dikembangkan, proses pengembangannya, dan menentukan batasanbatasan eksternal yang harus dipenuhi oleh produk tersebut.

a. Usability

Sistem memiliki tampilan (antar muka) yang mudah dipahami.

b. Portability

Sistem memiliki tampilan antarmuka (interface) yang responsive bagi mobile, ataupun tablet

\subsection{Desain Sistem}

Usecase dibuat berdasarkan dari kebutuhan fungsional dan non fungsional. Usecase berfungsi menjelaskan kebutuhan-kebutuhan aktor dalam sistem. Pada Gambar 2 merupakan use case diagram yang dibuat.

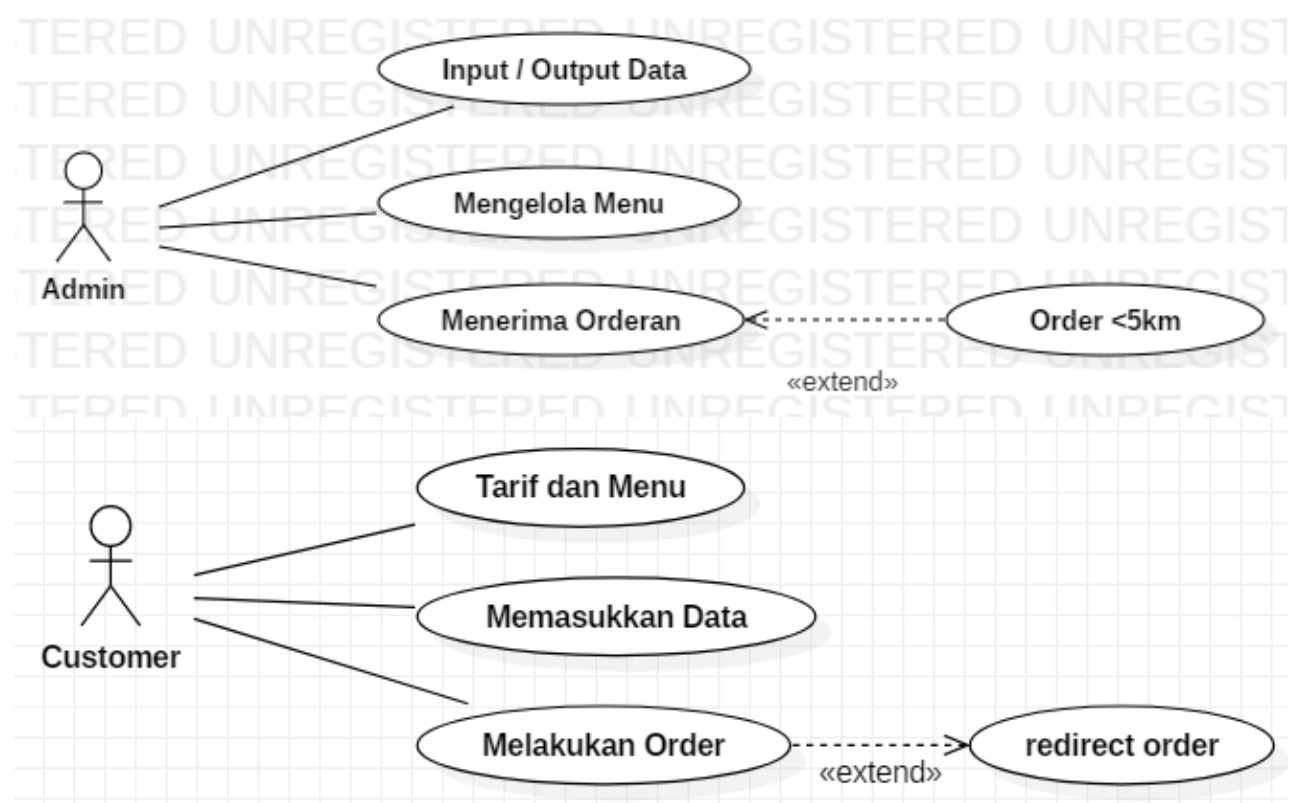

Gambar 2. Usecase Diagram Aplikasi Molly Molen

Dari usecase dibuat definisi use case, activity diagram, dan desain table diagram. Pada Gambar 3 merupakan desain table database dari aplikasi ini. 


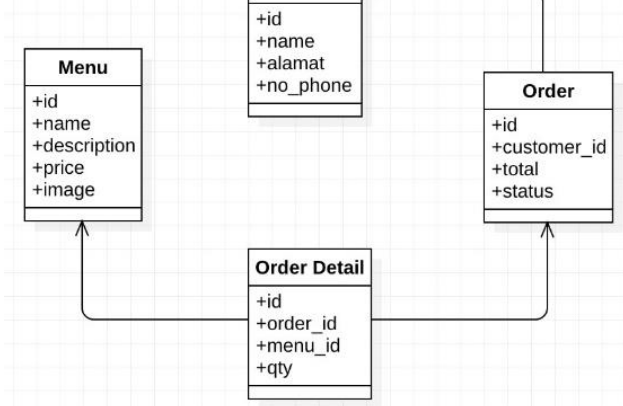

Gambar 3. Desain Database Aplikasi Kaderisasi

\section{Implementasi}

\subsection{Implementasi Database}

Implementasi database menggunakan MariaDB yang diakses melalui aplikasi web phpMyAdmin. Lewat aplikasi ini dapat dilakukan pengelolaan keseluruhan server MySQL (memerlukan super-user) dan basis data tunggal. phpMyAdmin juga mempunyai sistem internal untuk mengelola metadata dan mendukung fitur-fitur untuk operasi tingkat lanjut. Melalui sistem administrator, phpMyAdmin juga dapat mengelola users dan sekaligus hak aksesnya (privilage). Gambar 4 berikut implementasi database yang telah dilakukan.

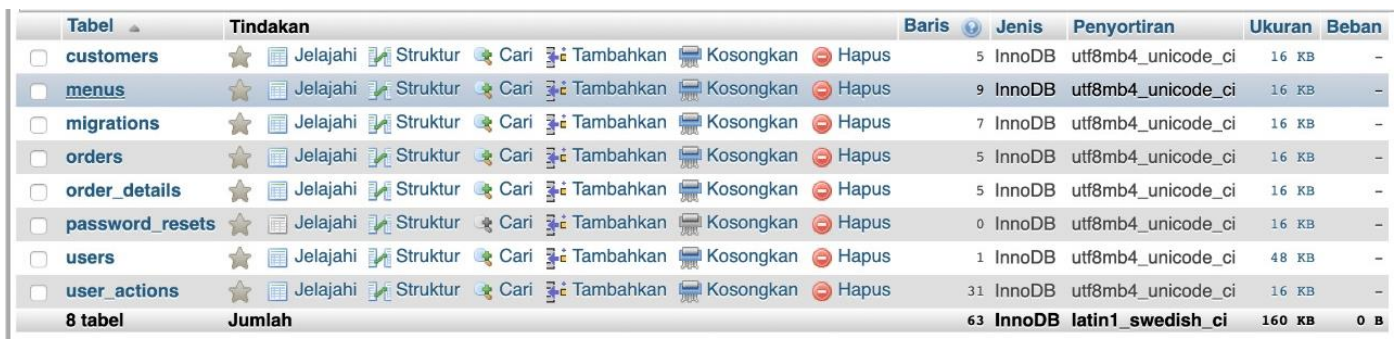

Gambar 4. phpMyAdmin List Tabel Dari Database Aplikasi Molly

\subsection{Implementasi Interface}

Interface Aplikasi Molly Mollen didesain responsif agar dapat menyesuaikan lingkungan aksesnya. Dalam implementasinya aplikasi ini menggunakan kodular yang memungkinkan ssesorang membuat aplikasi tanpa melakukan coding. Gambar 5 dan Gambar 6 berikut contoh implementasi interface kodular yang sudah dibuat.

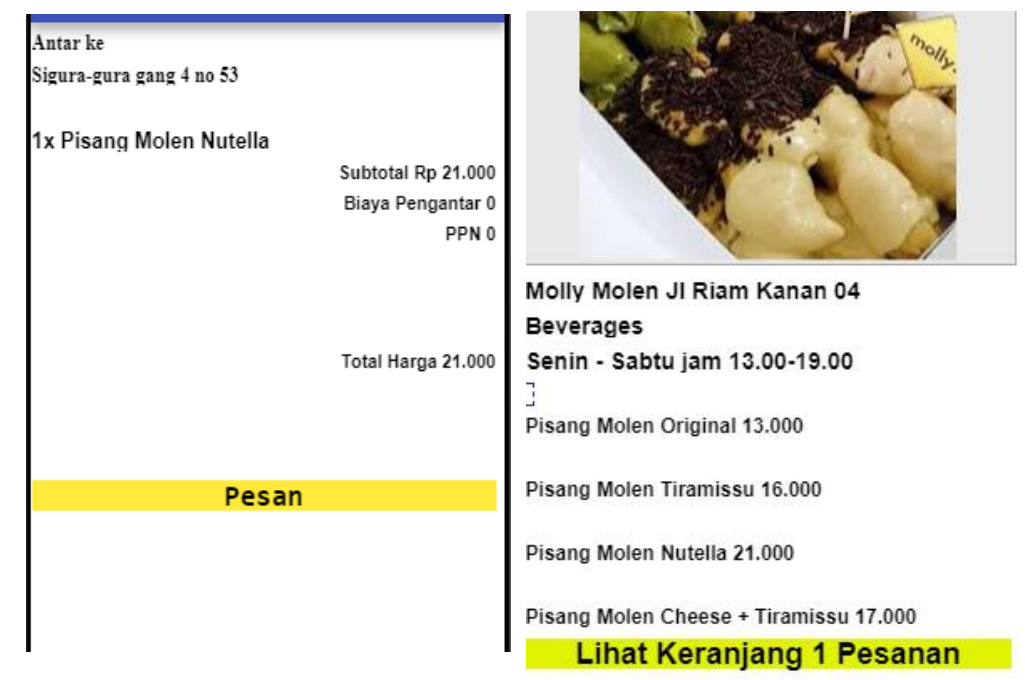

Gambar 5. Halaman Order Menu Molly 


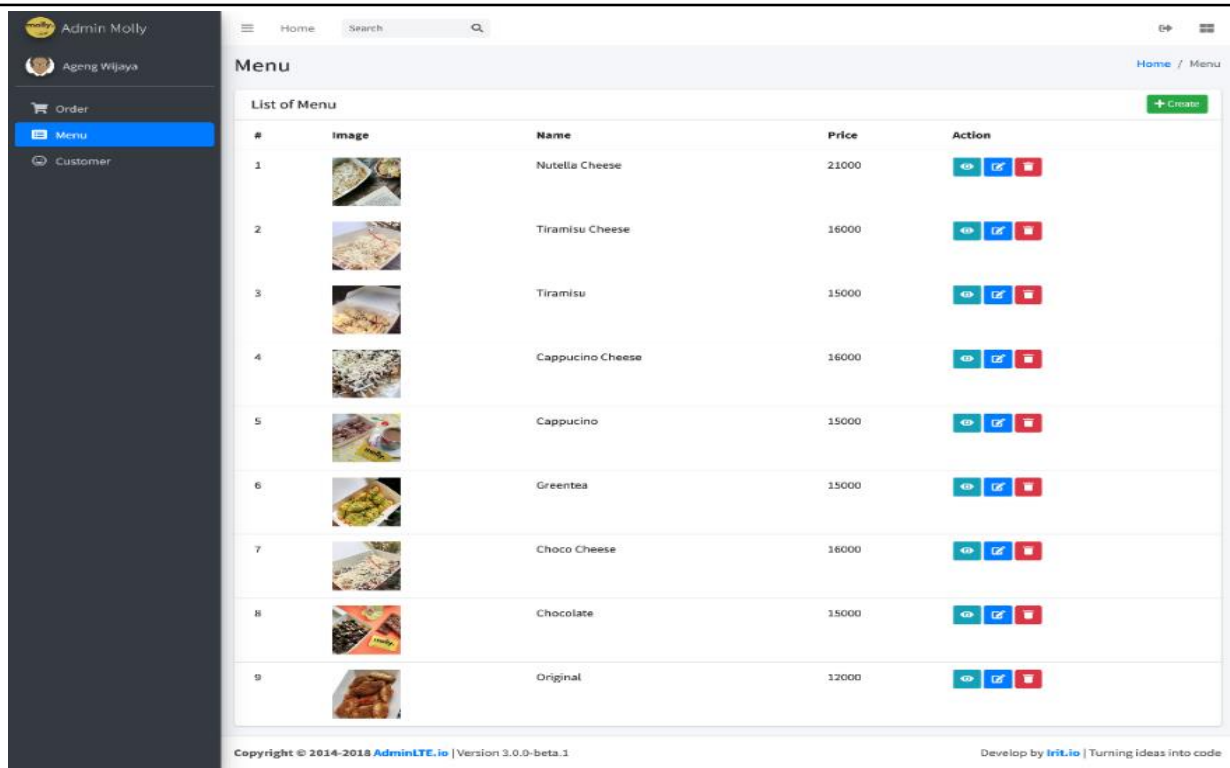

Gambar 6. Halaman Order Menu Molly

\section{Pengujian}

\subsection{Pengujian Fungsional}

Pada pengujian fungsional sistem digunakan metode black box dimana metode ini tidak memperhatikan logika suatu fungsional itu dibangun melainkan kesesuaian fungsi berjalan dengan yang diharapkan. Pengujian sistem ini akan dilakukan berdasarkan use case yang telah dijelaskan sebelumnya dengan menggunakan 4 user yaitu superadmin, admin, kader, dan kader petugas. Pada Tabel 1 merupakan adalah sebagian hasil pengujian:

Tabel 1. Hasil Pengujian Fungsional Aplikasi Kaderisasi

\begin{tabular}{ccc}
\hline Aktor & Case & Hasil \\
\hline \multirow{2}{*}{ Admin } & Kelola Menu & Sesuai \\
& Kelola Order & Sesuai \\
& Kelola Customer & Sesuai \\
\hline \multirow{2}{*}{ Customer } & Lihat Menu & Sesuai \\
& Order Menu & Sesuai \\
\hline
\end{tabular}

\section{Kesimpulan dan Saran}

Dari uraian pembahasan dan hasil pengujian yang dilaksanakan dalam penelitian ini, maka dapat diambil kesimpulan sebagai berikut:

1. Perancangan dan pembangunan aplikasi pemesanan molly molen Malang telah mampu dirancang dan dibangun berdasarkan tahapan dari metode waterfall.

2. Pengujian sistem aplikasi pemesanan molly molen Malang menggunakan blackbox. Aplikasi pemesanan molly molen Malang berjalan dengan baik secara fungsional dan menghasilkan output yang diharapkan.

Berdasarkan penyimpulan dari hasil pembahasan penelitian dalam skripsi ini, maka peniliti menyertakan saran pengembangan yang dapat dilakukan sebagai berikut:

1. Pengembangan lebih lanjut diharapkan adanya penelitian mengenai fitur pembayaran non tunai (ovo, gopay, dan auto debit atm).

2. Pengembangan aplikasi ini masih dalam lingkup android, dapat dikembangkan dalam sistem iPhone, serta dengan tampilan yang lebih menarik.

\section{Referensi}

[1] L. R. F. W. M. Hutabarat, "Strategi Pengembangan Usaha Kuliner di Kota Malang Berbasis Ekonomi Kreatif," J. Ekon. dan Stud. Pembang., vol. 7, no. 1, pp. 12-20, 2015.

[2] G. F. Suranta, "Analisis Strategi Pemasaran Jasa Menghadapi Pesaing," Anal. Strateg. Pemasar. Jasa Menghadapi Pesaing, vol. 1, no. 1, pp. 22-32, 2015.

REPOSITOR, Vol. 2, No. 7, Juli 2020: 855-862 
[3] W. R. Arifah, "Kuliner_Yummy, Pisang Molen Aneka Rasa Ala Malang _ Malang TIMES," Debyawan Dewantara Erlansyah, 2018. .

[4] L. Affandi, R. Rismanto, and M. M. Firmansyah, "Aplikasi pengiriman pesanan makanan menggunakan algoritma djikstra," Tugas AKhir, pp. 1-10, 2017.

[5] P. D. I. Ra'uufi and Y. Sinatra, "Rancang Bangun Aplikasi Delivery Order Berbasis Android Di Ageng Bakery Group Blitar," 2015.

[6] H. La Saputri, "Pengembangan Sistem Online Delivery ' Food Mambo ,'” vol. 2014, no. semnasIF, pp. 84-91, 2014.

[7] V. N. Nore, "Perancangan Sistem Informasi Penjualan Dan Pemesanan Produk Berbasis Web (Studi Kasus Di Cv. Richness Development Bandung)," Skripsi, pp. 1-111, 2013.

[8] R. Febriani, Y. D. Lestari, D. A. Yudangga, and S. F. Damara, "FONDE : Aplikasi Pemesanan Makanan pada Perangkat Android melalui Media Sosial," Pros. Sentrinov, vol. 001, pp. 301312, 2015.

[9] S. Dian, H. Permana, and M. R. Fauzi, "Rancang Bangun Aplikasi Pemesanan Dan Transaksi ( Studi Kasus: Fst Universitas Trilogi )," J. Sist. Inf., vol. 5, no. 1, pp. 504-513, 2015.

[10] R. A. Sagita and H. Sugiarto, "Penerapan Metode Waterfall Pada Sistem Informasi Penjualan Furniture Berbasis Web," ndonesian J. Netw. Secur., vol. 5, no. 4, pp. 49-55, 2016.

[11] Nurasiah, "Perencanaan Pengembangan Sistem Informasi Pembayaran Uang Kuliah Dengan Metode SDLC Waterfall," J. Teknol. dan Rekayasa, vol. 19, no. 3, pp. 72-81, 2014.

[12] A. Saxena and P. Upadhyay, "Waterfall vs . Prototype : Comparative Study of SDLC," Imp. J. Interdiscip. Res., vol. 2, no. 6, pp. 1012-1015, 2016.

[13] E. T. Informatika et al., "Rancang Bangun Aplikasi Pemesanan Menu Makanan Restoran Berbasis Android," vol. 9, no. 1, pp. 1-9, 2016.

[14] Kodular, "Documentation Kodular," 2019. [Online]. Available: https://docs.kodular.io/.

[15] R. Ariyanti and I. Kanedi, "Pemanfaatan Google Maps Api Pada Sistem Informasi Geografis Direktori Perguruan Tinggi Di Kota Bengkulu," vol. 11, no. 2, pp. 119-129, 2015. 
REPOSITOR, Vol. 2, No. 7, Juli 2020: 855-862 